Journal of the Electrochemical Society, Vol. 145, No. 8, 1998, pp. 2831-2840.

ISSN: 0013-4651

DOI: $10.1149 / 1.1838722$

http://www.electrochem.org/

http://scitation.aip.org/getpdf/servlet/GetPDFServlet?filetype=pdf\&id=JESOAN000145000008002834000001\&idty pe $=$ cvips\&prog $=$ normal

(C) The Electrochemical Society, Inc. 1998. All rights reserved. Except as provided under U.S. copyright law, this work may not be reproduced, resold, distributed, or modified without the express permission of The Electrochemical Society (ECS). The archival version of this work was published in Journal of the Electrochemical Society, Vol. 145, No. 8, 1998, pp. 2831-2840.

\title{
Pitting in Aluminum Thin Films Supersaturation and Effects of Dichromate Ions
}

\author{
A. Sehgal,* D. Lu,* and G. S. Frankel** \\ The Fontana Corrosion Center, Department of Materials Science and Engineering, The Ohio State University, \\ Columbus, Ohio \\ * Electrochemical Society Student Member. ** Electrochemical Society Active Member.
}

\begin{abstract}
The growth of pits in $209 \mathrm{~nm}$ thick Al films in chloride solutions with and without dichromate ions was examined using image analysis of the growing pits to determine pit current density. In pure chloride solutions, the pit current density decreased at high potentials after reaching a maximum value, and then was almost independent of applied potential. A hysteresis in the pit current density-potential behavior was observed during downward stepping of the potential from high values. This is a result of a combination of supersaturation of the pit electrolyte followed by salt film formation, and changes in mass transport from hydrogen bubbles that increase convection and lift the remnant passive film away from the dissolving surface. In solutions containing dichromate ions, the corrosion and repassivation potentials shifted in the noble direction, and rather large metastable pits formed at the open circuit. A large concentration of dichromate ions was needed to inhibit pit growth. In dichromate solutions, subsequent pit growth at higher potentials often initiated at the edge of the open-circuit pits. The rate of pit growth was lower for these pits because the remnant passive film layer was not easily lifted up at these sites, and thus created a barrier for mass transport away from the dissolving pit edge.
\end{abstract}

\section{Introduction}

Pits in thin metallic films (on the order of tens or hundreds of nanometers in thickness) deposited on inert substrates penetrate through the metal layer in a fraction of a second. ${ }^{1-4}$ They then grow outward with the active pit area perpendicular to the substrate and increasing pit radius. Since the aspect ratio (pit radius to depth) of pits in thin films is large, they may be considered to be two-dimensional. The $2 \mathrm{D}$ pits in thin films grow in a steady-state fashion with a constant pit depth equal to the metal film thickness, instead of the ever-increasing pit depth of pits in bulk samples. As a result, the pit current density, determined by analysis of images of the growing pit, is constant with time and independent of pit size at a given pit growth potential. The pitting process is simplified by limiting the metal dimension in one direction. Furthermore, since the pit depth can be carefully controlled by the thin film deposition process, it is possible to probe pits having a range of steady-state thicknesses, down to very small values. These pits are 2D steady-state analogs to very small pits in bulk samples. By studying pits in increasingly thinner metallic films, it is possible to simulate the growth of extremely small pits in bulk 
samples. This approach thereby overcomes the problem that very small pits in bulk samples quickly become large.

The first study of pitting in thin films used pure $\mathrm{Al}$ films about $150 \mathrm{~nm}$ in thickness in 0.1 $\mathrm{M} \mathrm{NaCl} .{ }^{1}$ The potential was raised slowly until pitting initiated, and then was held at the pitting potential. Single pits were formed in this fashion, and the natural variation in pitting potential provided a range of applied potential. The anodic pit current density was determined using analysis of images of growing pits and Faraday's law to relate the pit perimeter velocity to anodic pit current density. The pit current density generally increased with applied potential, reaching what seemed to be a limiting current density at the high potential region where the pits were very round in shape. This indicated that the pits at the high potentials were under mass-transport control, growing with a salt film in equilibrium with a saturated solution at the active pit surface. Pits in the lower potential region where the pit current density varied approximately linearly with potential were suggested to be growing under ohmic or mixed ohmic/charge-transfer control. This system is revisited in the present study, and somewhat different results were obtained.

The current density-potential $(i-E)$ relation was determined for pits in Ni-20Fe films with a range of thickness. ${ }^{2}$ The limiting current density and the slope, di/dE, in the lower potential region were both found to increase as the film thickness decreased. Furthermore, a critical potential and current density were found for each film thickness below which pit growth could not be maintained and the pits repassivated. A model was developed to describe the $i$ - $E$ curves, and their variation with thickness. It was suggested that a barrier to mass transport existed at the pit surface because the limiting pit current densities were lower than what would be predicted by simple mass transport models. The undermined passive film, which is not lifted up by hydrogen bubbles as in the case of Al, was offered as being the transport barrier. The behavior in the lower potential region was modeled using a potential component calculation. Ohmic, charge-transfer, and concentration considerations were all found to be important, with ohmic potential drops becoming the dominating factor as the film thickness increased. Using the assumption presented above, that pits in thin films are steady-state analogs to small pits in bulk samples, one could consider that similar limitations to growth hold for deepening 3D pits.

The 2D pit growth technique was also used to study the remarkable pitting resistance of some of sputter-deposited Al binary alloys. ${ }^{3}$ The influence of the passive film on the pitting process was shown to be minor compared to the effect of the ennoblement of the pit dissolution process by alloying. Higher potentials were needed to generate a large enough pit current density to sustain the critical environment needed to prevent repassivation in alloyed films. The stability of pits can be seen to result from a cascading chain of causality: potential $\rightarrow$ pit current density $\rightarrow$ local environment $\rightarrow$ repassivation.

The effect of film thickness (or pit depth) on repassivation of pits in Al films ranging in thickness from $10 \mathrm{~nm}$ to $43 \mu \mathrm{m}$ was studied. The repassivation potential first decreased as thickness increased from 10 to $435 \mathrm{~nm}$, and then increased as the film thickness increased further. Mass-transport and ohmic resistance both increase as the metal film thickness increases, but the former enhances pit stability and the latter destabilizes pitting in this system. Pit repassivation, and thus stability, are strongly influenced by mass transport considerations for pits in very thin films, even though dissolution at low potentials is not under pure mass-transport control. Ohmic effects become increasingly important as the film thickness increases.

In the current investigation, the full pit polarization curve was determined over a wide range of potentials for pits in Al thin films. The influence of dichromate ions dissolved in the chloride solution was also examined. Previous work has shown that chromate ions reduce the 
tendency for pitting in $\mathrm{Al}$, and the amount of chromate required to have an effect depends on the amount of chloride present and the aspect of pitting corrosion under study. ${ }^{5-7}$ The growth rate of large pits through $\mathrm{Al}$ foils up to $0.2 \mathrm{~mm}$ in thickness in $0.01 \mathrm{M} \mathrm{NaCl}$ was not affected unless 0.1 $\mathrm{M} \mathrm{NaCrO}_{4}$ was added, a 10:1 chromate:chloride ratio. ${ }^{5}$ The pitting potential of $\mathrm{Al}$ was found to increase only if the chromate:chloride ratio was about $1: 1{ }^{6}$ Metastable pitting of Al was strongly reduced when the chromate:chloride ratio was only about $0.01 .^{7}$ So, the amount of chromate needed to affect pitting seems to increase as the scale of the pits increases. In this work the effects of different dichromate to chloride ratios in 0.1 and $1.0 \mathrm{M}$ chloride solutions on the pit growth of 2D pits in $209 \mathrm{~nm}$ thick Al films were investigated.

\section{Experimental}

Al films were deposited onto glass substrates at a thickness of $209 \mathrm{~nm}$ by direct current magnetron sputtering from a $99.999 \%$ pure Al target in a tool with a base pressure of about $2 \times$ $10^{-7}$ Torr. The electrochemical cell was assembled using a backing plate to hold the Al thin film sample against a polytetrafluoroethylene o-ring at the bottom of a polymethylmethacrylate cell (Fig. 1). The exposed area was $0.82 \mathrm{~cm}^{2}$. A Pt counter electrode and a saturated calomel reference electrode completed the three-electrode cell. The electrolyte was unstirred and open to air. A quartz sleeve in the cell cover allowed for insertion of an optical probe for recording images of the growing pits on videotape, similar to what was done in previous investigations. ${ }^{1-4}$

The potential was controlled by front panel operation of an EG\&G PAR 273 potentiostat. It was scanned at $1 \mathrm{mV} / \mathrm{s}$ from the open-circuit potential until a pit initiated as indicated by a sharp increase in the current, and the observation of a pit through the video system. The potential was held at the pitting potential, and images of the growing pits recorded. Two different approaches were then utilized for subsequent control of the potential. In the first, the potential was increased (in the noble direction) sequentially in increments of varying size. This is the "step-up" approach. The hold time at each potential was long enough to record sufficient images of the growing pits for subsequent analysis, and varied from 10 to $120 \mathrm{~s}$ depending on the rate of pit growth. Since 2D pits in thin films grow at steady state, the extent of prior growth has no effect, and thus, the hold time at a given potential does not affect the growth.

In the second potential-controlling approach, called "step-down," the potential was stepped directly to a high potential after pit initiation, followed by sequential stepping to increasingly less noble values, with the steps long enough to capture images of the growing pit. In some of the step-up experiments, the potential step direction was reversed to combine step-up and step-down measurements in the same run. 


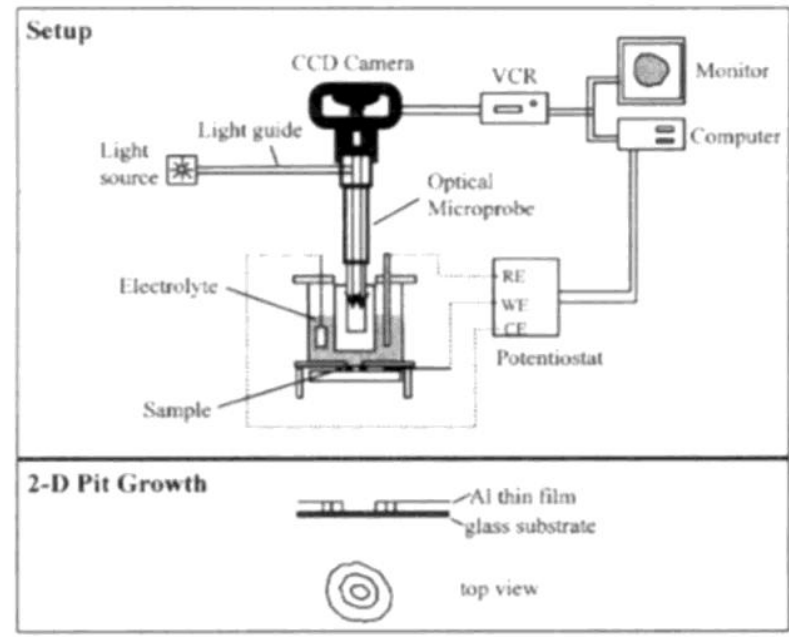

Fig. 1. Schematic drawings of the experimental setup and of the nature of two-dimensional pit growth in thin films.

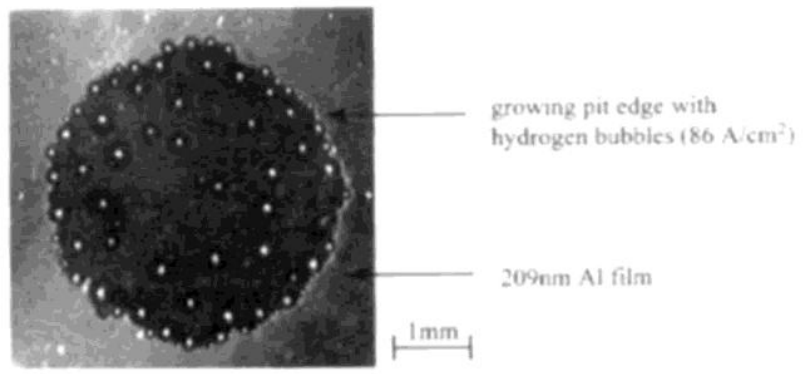

Fig. 2. Video image of a pit growing in a $209 \mathrm{~nm}$ thick $\mathrm{Al}$ film in $1.0 \mathrm{M} \mathrm{NaCl}$ at an applied potential of $450 \mathrm{mV}$ SCE.

The anodic pit current density was determined by analysis of the images of the growing pits as described previously. ${ }^{1-4}$ The amount of hydrogen evolved during thin film pit growth increases with increasing film thickness. ${ }^{4}$ For the $209 \mathrm{~nm}$ thick samples, the pit perimeter was sufficiently obscured by hydrogen bubbles that automated image analysis was not possible. Figure 2 is an image of a pit growing in $1.0 \mathrm{M} \mathrm{NaCl}$ solution. The tops of the bubbles reflect the incident light and show up bright, and slightly out of focus since the bubble top was above the metal film surface, which was in focus. Bubbles were seen to decorate much of the perimeter, and also were left in the interior of the pit on the glass substrate as the edge moved away during pit growth. As described previously, it is possible in this case to determine the pit current density using Faraday's law and manual assessment of the pit wall velocity on the monitor during playback after an experiment. ${ }^{4}$ Several measurements were made at different locations on the pit perimeter and an average was taken. In most cases, the measured pit velocities at different points of the same pit were very close. In other experiments, however, there were certain regions along a pit wall that exhibited a slower rate of dissolution, and an undermined passive film remnant 
was visible near those regions. Measurements made at these locations were not averaged and are reported and discussed separately.

\section{Results and Discussion}

Chloride solutions. - The pit current density for pits in $209 \mathrm{~nm}$ thick Al films in 0.1 and $1.0 \mathrm{M} \mathrm{NaCl}$ is given in Fig. 3 and 4, respectively, as a function of applied potential. The data points on these curves represent average values at each potential from several different experiments. Although the curves show average data, they reproduce the trend observed in individual experiments very well. This is discussed in detail later. In both figures, the pit current densities determined by stepping the potential in the noble direction are separated from those determined in experiments in which the potential was stepped down in the active direction.

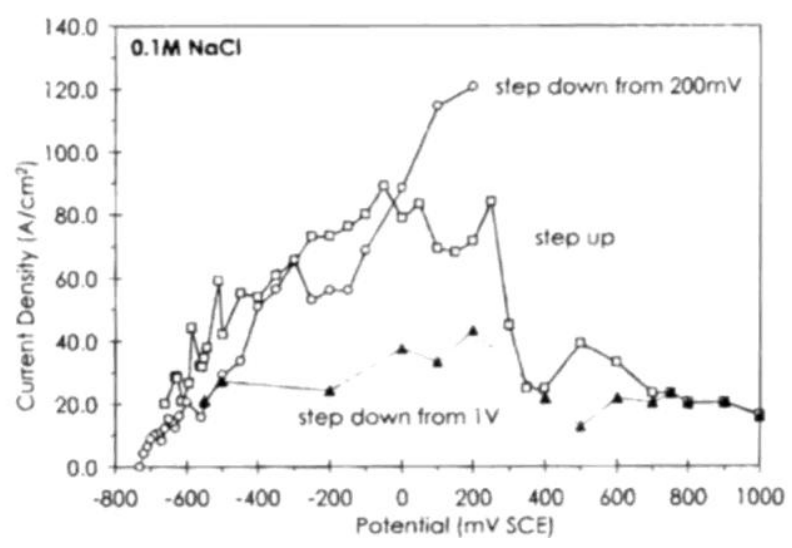

Fig. 3. Average anodic pit current density as a function of applied potential for pits in $209 \mathrm{~nm}$ thick Al films in $0.1 \mathrm{M} \mathrm{NaCl}$.

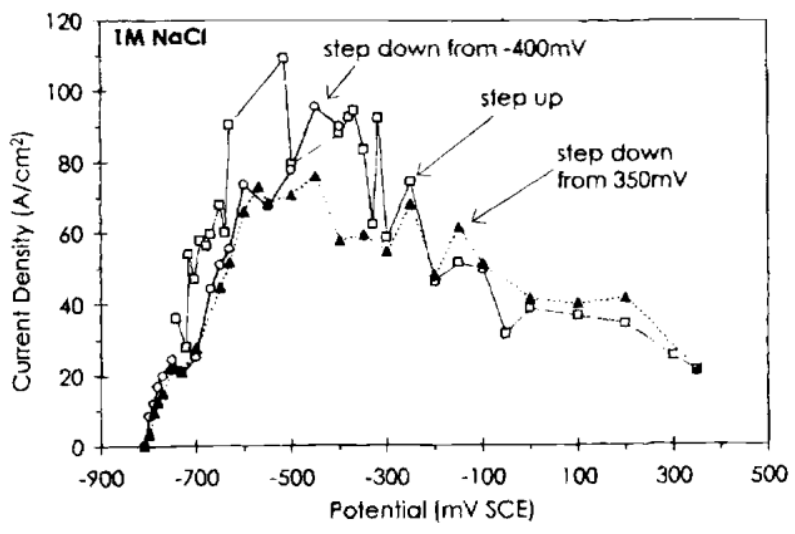

Fig. 4. Average anodic pit current density as a function of applied potential for pits in $209 \mathrm{~nm}$ thick Al films in $1.0 \mathrm{M} \mathrm{NaCl}$. 
Furthermore, the downward-stepped experiments were divided into those that started at very high potentials and those starting at or below a peak value in the upward-stepping curve (+200 and $-400 \mathrm{mV}$ saturated calomel electrode (SCE) for the 0.1 and $1.0 \mathrm{M} \mathrm{NaCl}$ solutions, respectively). In both solutions, the upward and downward curves converge in the low potential region just above the repassivation potentials, which on average are -726 and $-806 \mathrm{mV}$ SCE for the 0.1 and $1.0 \mathrm{M} \mathrm{NaCl}$ solutions, respectively. These repassivation potentials are similar to those reported earlier. ${ }^{4}$ It has been suggested previously that thin film pits are under ohmic or mixed ohmic/ charge-transfer control at potentials closest to the repassivation potentials where the $i$-E curves are almost linear. ${ }^{1-4}$ The coincidence of the upward- and downward-stepping polarization curves further support the notion of ohmic or mixed ohmic/charge-transfer control in this region. In fact, ohmic influences likely dominate charge-transfer effects.

The data for the $0.1 \mathrm{M}$ solution, Fig. 3, are different from those reported previously for somewhat thinner $\mathrm{Al}$ films in the same solution. ${ }^{1}$ In that first work on pit growth in thin films, pits were maintained at the breakdown potential, and only one current density was determined for each sample at the breakdown potential for that sample. This approach promotes the formation of a single pit, but limits the amount of data that can be obtained compared to the approach of stepping to multiple potentials in one experiment with a single sample. Data reported in the earlier work suggested that a limiting current density of about $30 \mathrm{~A} / \mathrm{cm}^{2}$ was reached at about $-580 \mathrm{mV} \mathrm{SCE}$ in $0.1 \mathrm{M} \mathrm{NaCl} .{ }^{1}$ Figure 3 indicates a limiting current density of about $80 \mathrm{~A} / \mathrm{cm}^{2}$ at potentials in the range of -200 to $+200 \mathrm{mV} \mathrm{SCE}$ during upward-stepping of the potential in $0.1 \mathrm{M} \mathrm{NaCl}$. The pit current density is thus higher for the thicker films used in this study despite the previous finding that limiting current densities decrease as the film thickness increases for pits in $\mathrm{NiFe}$ films. ${ }^{2}$ At higher potentials, the current density is seen to decrease markedly to about 20 to $30 \mathrm{~A} / \mathrm{cm}^{2}$. This decrease is observable in a single experiment and is quite noticeable on the videotape during viewing as a decrease in the velocity of the pit perimeter. Given the high dissolution rates in the high-current region, only very brief pauses (10 s) were possible at each potential in that range. (At $100 \mathrm{~A} / \mathrm{cm}^{2}$, the pit perimeter velocity is about $30 \mu \mathrm{m} / \mathrm{s}$, or $3 \mathrm{~mm} / \mathrm{s}$ on the video monitor considering the 100 times magnification used.) Nonetheless, the decrease in current density at high applied potentials is obvious. At potentials above about $300 \mathrm{mV} \mathrm{SCE}$ the current density is again found to be rather independent of applied potential, but at the much lower value of $20-30 \mathrm{~A} / \mathrm{cm}^{2}$, which is close to the limiting current density found in the earlier work.

Similar behavior is observed for the case of $1.0 \mathrm{M} \mathrm{NaCl}$ solution (Fig. 4). A limiting current density of about $80-100 \mathrm{~A} / \mathrm{cm}^{2}$ is exhibited in the potential range of about -625 to -325 $\mathrm{mV} \mathrm{SCE}$ for the upward-stepping experiments Compared to the $0.1 \mathrm{M} \mathrm{NaCl}$ solution, higher pit current densities are obtained at lower potentials in the more concentrated solution because the solution conductivity and thus the slope of the $i-E$ curve are higher. A decrease in the current density is observed at high potentials for the upward-stepped experiments, but it is gradual and certainly not as sharp as that seen for the $0.1 \mathrm{M} \mathrm{NaCl}$ solution.

The pit current densities determined during downward-stepping of the potential in both solutions are somewhat different to those found during upward-stepping. In $0.1 \mathrm{M} \mathrm{NaCl}$, a large hysteresis is seen for samples stepped downward from potentials above $200 \mathrm{mV}$, with the current density being lower in the mid-potential region during downward stepping. The current density is practically independent of applied potential over a very wide range, and similar to the highpotential value of about $20 \mathrm{~A} / \mathrm{cm}^{2}$. In contrast, no hysteresis is observed for samples stepped down from potentials below $200 \mathrm{mV}$ SCE. If anything, the current densities measured in the 
range of 0 to $200 \mathrm{mV} \mathrm{SCE}$ were higher than those found during upward stepping. However, in the lower potential region, the upward-and downward-stepped experiments exhibit similar current densities for samples stepped down from potentials below $200 \mathrm{mV}$ SCE.

A much smaller hysteresis is observed in the $1.0 \mathrm{M} \mathrm{NaCl}$ solution. The current density values increase slowly during the step-down experiments from the high potential range to around $-575 \mathrm{mV}$ SCE in a fashion that is almost identical to the slow decrease observed in the upwardstepping experiments. Since this slope is gradual, and no sharp decrease is observed in the upward-stepping experiments, only a small hysteresis is observed. In the range of -575 to -350 $\mathrm{mV} \mathrm{SCE}$, the pit current density measured during downward-stepping is slightly lower than that measured during upward-stepping. At potentials below $-600 \mathrm{mV}$, the current-density/potential relationship is similar for all conditions.

It should be noted that the points shown in Fig. 3 are average values obtained from several experiments. The gradual change in current density for the $1.0 \mathrm{M} \mathrm{NaCl}$ solution in the range of -300 to $0 \mathrm{mV} \mathrm{SCE}$ is really an artifact of this averaging. Most experiments exhibited a sharper increase or decrease in current density, but the value at which the transition occurred varied over a wide range from experiment to experiment. In some step-down experiments, in fact, the current density stayed at the high potential value all the way back to low potentials without increasing. By averaging many runs, this variation is smoothed out, so that Fig. 4 is not perfectly representative of the $i$ - $E$ relationship. It should be clear, however, that most downwardstepping experiments in $1.0 \mathrm{M} \mathrm{NaCl}$ exhibited an increase in current density above the highpotential current values.

The decrease in current density at high potentials and hysteresis upon downward-stepping can be explained by either a supersaturation of the electrolyte and precipitation of a salt film on the sample surface, or changes in the effects of hydrogen bubbles as a function of potential. Most likely, both influences are important in this case.

Supersaturation and salt film precipitation phenomena in artificial pit electrodes have been described by Isaacs and Newman. ${ }^{8}$ Salt films often will not precipitate on a dissolving metal surface until the solution adjacent to the surface supersaturates to a concentration well above the saturation concentration that is in equilibrium with the salt film after it forms. As a result, the rate of dissolution, i.e., the pit current density, can be much larger just before the salt film forms compared to afterward. Supersaturation leads to a hysteric pit polarization curve because the salt film, once formed, remains in equilibrium with the saturation concentration solution during downward scanning until a transition potential at which the salt film dissolves and the pit is no longer under diffusion control. If the whole observed drop in current density were due to supersaturation, it would be possible to determine the extent of supersaturation from the ratio of the current densities just before and just after the drop. For the $0.1 \mathrm{M} \mathrm{NaCl}$ case, this would indicate a supersaturation concentration of about 2.5 times the saturation value. Assuming a saturation concentration for $\mathrm{A}_{1 \mathrm{Cl}_{3}}$ of $3.1 \mathrm{M}$, ${ }^{9}$ the supersaturation concentration would be estimated at $7.7 \mathrm{M}$ according to this line of thought. Since the decrease in potential for the $1.0 \mathrm{M}$ $\mathrm{NaCl}$ case was gradual, it is difficult to make the same assessment of supersaturation. The higher bulk chloride concentration also needs to be considered. Assuming current densities before and after salt film precipitation of 80 and $40 \mathrm{~A} / \mathrm{cm}^{2}$, respectively, a supersaturation concentration of 5.9 $\mathrm{M}$ is obtained. Given the shape of the curves, however, there is more error associated with this estimation.

Furthermore, it is likely that the whole decrease in current density is not a result of supersaturation. As mentioned, differences in hydrogen evolution will affect the pit current 
density. It is interesting to note that hydrogen bubbles form at the dissolving pit walls in these thin film pits even at very high applied potentials. Assuming a pit $\mathrm{pH}$ of $3,{ }^{10}$ the reversible potential for the hydrogen evolution reaction would be $-421 \mathrm{mV} \mathrm{SCE} .{ }^{11}$ Hydrogen bubbles have been observed at applied potentials as high as $600 \mathrm{mV} \mathrm{SCE}$; no bubbles were seen in any experiment at potentials above $600 \mathrm{mV}$ SCE. The resistance associated with concentration of the current density into the microband electrode that forms the active pit wall results in considerable infrared drop (up to $1 \mathrm{~V}$ ) throughout the whole potential range examined, which permits the formation of hydrogen gas on the pit wall even at applied potentials as high as $600 \mathrm{mV}$ SCE. There is clear evidence that hydrogen bubbles formed in Al pits affect the local mass transport conditions and the pit current density. For the case of pits in NiFe thin films where no hydrogen evolution is observed, it was shown that the undermined passive film is not lifted away from the dissolving pit surface as in the case of $\mathrm{Al}$ pits, resulting in an additional barrier to mass transport. ${ }^{2}$ The presence of hydrogen bubbles certainly enhances the mass transport in the case of Al by lifting this passive film remnant away from the surface. The observation that higher limiting current densities are observed for the thicker Al films in this study compared to that observed previously ${ }^{1}$ may be a result of the larger film thickness and the corresponding larger amount of total hydrogen generated. The more hydrogen gas generated, the more effective it would be at both lifting the passive film remnant and also enhancing convection. Enhanced convection leads to an increase in the limiting current density via a decrease in the diffusion layer thickness.

As the applied potential, and thus the pit wall potential are increased, there will eventually be a decrease in the rate of hydrogen evolution. The pit wall potential must be much lower than the applied potential because of the very large IR drop, but its value is not clearly known at any point along the polarization curve. However, if the hydrogen evolution reaction decreases sufficiently as the potential is increased, the pit current density would decrease as a result of less convection and lifting of the passive film remnant. Hydrogen bubbles are still seen at the pit edge in a portion of the high potential region (400 to $600 \mathrm{mV} \mathrm{SCE}$ ) so the decrease in current cannot be fully explained by elimination of the hydrogen reaction, and it is likely that salt film precipitation does take place when the current density drops. On the other hand, it is also likely that the extent of hydrogen evolution is less on the salt-covered surface compared to the actively dissolving Al pit wall. So, the act of precipitating a salt film might effectively decrease the hydrogen evolution current and thus further reduce the current beyond the reduction associated with supersaturation and precipitation. The fact that a hysteresis is observed supports the notion of supersaturation and precipitation. However, as described above, most downwardstepping experiments in $1.0 \mathrm{M} \mathrm{NaCl}$ exhibited an increase in potential above the high-potential limiting current value, and not a true hysteresis as expected for salt film covered electrodes. This type of increase would support the mechanism of hydrogen evolution variations, which might be reversible. However, it is also possible that the salt film on the walls of these thin film pits is easilydisrupted in the high chloride solution. This disruption might result from the hydrogen bubbles themselves. If the salt film is removed during step-down experiments in the potential region where supersaturation is observed during step-up experiments, the current would increase back to the values measured during the step-up tests.

In summary, the current density decrease and associated hysteresis observed for pits in $\mathrm{Al}$ thin films in chloride solutions appears to be mostly due to supersaturation of the electrolyte and precipitation of a salt film. Some influence of a potential-dependent hydrogen evolution reaction on the mass-transport near the pit wall is also likely. 
Dichromate-containing solutions.-In dichromate-containing solutions, the open-circuit potential is ennobled so that pits form at open circuit upon immersion of the electrode. Chromate is an oxidizing agent since the reversible potential for chromate reduction to $\mathrm{Cr}$ (III) oxide in neutral solution is in the range of 192 to $334 \mathrm{mV} \mathrm{SCE}$, depending on the form of the oxide." The oxidizing power of chromates initiates pits at open circuit, but these pits are essentially metastable pits in that in most cases they do not continue to grow. However, they can achieve a diameter on the order of $1.0 \mathrm{~mm}$. Such pits do not form at open circuit in chromate-free chloride solutions. Even small pits in the thin film samples can be easily seen during an experiment because they are transparent and show up in the video system as bright spots if illuminated by transmitted light only. Optical and scanning electron micrographs of a sample that was simply immersed for 3 min in $0.1 \mathrm{M} \mathrm{NaCl}+0.5 \mathrm{M} \mathrm{Na}_{2} \mathrm{Cr}_{2} \mathrm{O}_{7}$ are shown in Fig. 5. With illumination by incident light, the pit appears dark. The irregular shape of this pit is similar to that of pits that are typically seen growing under potentiostatic control at potentials just above the repassivation potential. Earlier publications have shown images of such pits, which are quite different in nature from the pits with smooth edges that grow at higher potentials. ${ }^{1}$ The center of the scanning elecron microscope (SEM) image in Fig. 5b is one small portion of the pitted region. The broken apart passive film remnant is clearly seen. The material to either side of the pitted area is the metallic Al film, as determined by a strong Al EDS signal that is absent in the central area. The metallic region to the top right of the pitted area is brighter than the region to the lower left because it is electrically isolated from the main part of the $\mathrm{Al}$ film and is thus charging under the electron-beam, even with a very low accelerating voltage of $2 \mathrm{kV}$.

As the potential is increased from open circuit in a typical experiment in a chloride + dichromate solution, further pit growth often initiates at a site associated with these open-circuit pits. Pits may also initiate at other sites that are apparently isolated from such defects. The pit growth emanating from the original open-circuit pits is often different than that observed even in the same experiment for pits that are initiated at other sites; the current density of pits growing from these original pits is typically much lower than that at pits initiated at other sites. Pits initiated away from the open-circuit pits grow with hydrogen bubbles at the pit edge, just as in
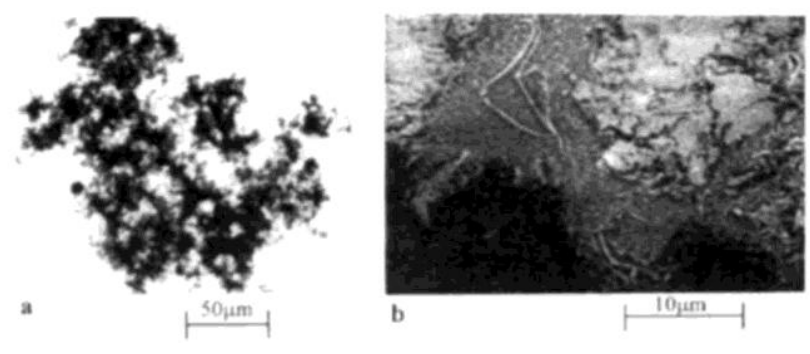

Fig. 5. Metastable pit formed during a $5 \mathrm{~min}$ immersion at open circuit in $1 \mathrm{M} \mathrm{NaCl}+0.5 \mathrm{M} \mathrm{Na}_{2} \mathrm{Cr}_{2} \mathrm{O}_{7}$. (a) Optical micrograph, (b) SEM with an accelerating voltage of $2 \mathrm{kV}$.

the case of pure chloride solutions. In contrast, pits that initiate at open-circuit pits do not have hydrogen bubbles decorating the pit edge. Instead, small bubbles can be seen to move quickly away from the pit edge along the glass substrate toward the center of the dissolved pit region and then escape from a spot away from the pit edge. It is presumed that the bubbles are moving under 
an intact passive film remnant and escaping at a place where this film is broken. Compared to the case where bubbles form at the surface and lift up the passive film, this added barrier results in a decrease in the pit growth rate or pit current density. Figure 6 shows an image of a pit growing away from an open-circuit pit $\left(E_{\mathrm{oc}}=-701 \mathrm{mV} \mathrm{SCE}\right)$ in $1 \mathrm{M} \mathrm{NaCl}+0.5 \mathrm{M} \mathrm{Na}, \mathrm{Cr}_{2} \mathrm{O}_{7}$. The opencircuit pit is seen as an irregularly shaped region. The dark area is the pit growth that initiated at $646 \mathrm{mV} \mathrm{SCE}$ at the edge of open-circuit pit. The potential was then stepped upward to different values; this image was taken at $-550 \mathrm{mV}$ SCE. In this particular pit, there are two distinct regions that are growing at different rates. The perimeter at the top left of the image is decorated with bubbles. It has moved further away from the original pit than the other areas, which are not decorated with bubbles. The passive film remnant was apparently broken away at this one region, resulting in a higher local pit current density. Pits that initiate at sites that are removed from the open-circuit pits in this solution typically grow with hydrogen bubbles decorating the pit perimeter and at a high rate similar to the top left region in Fig. 6.

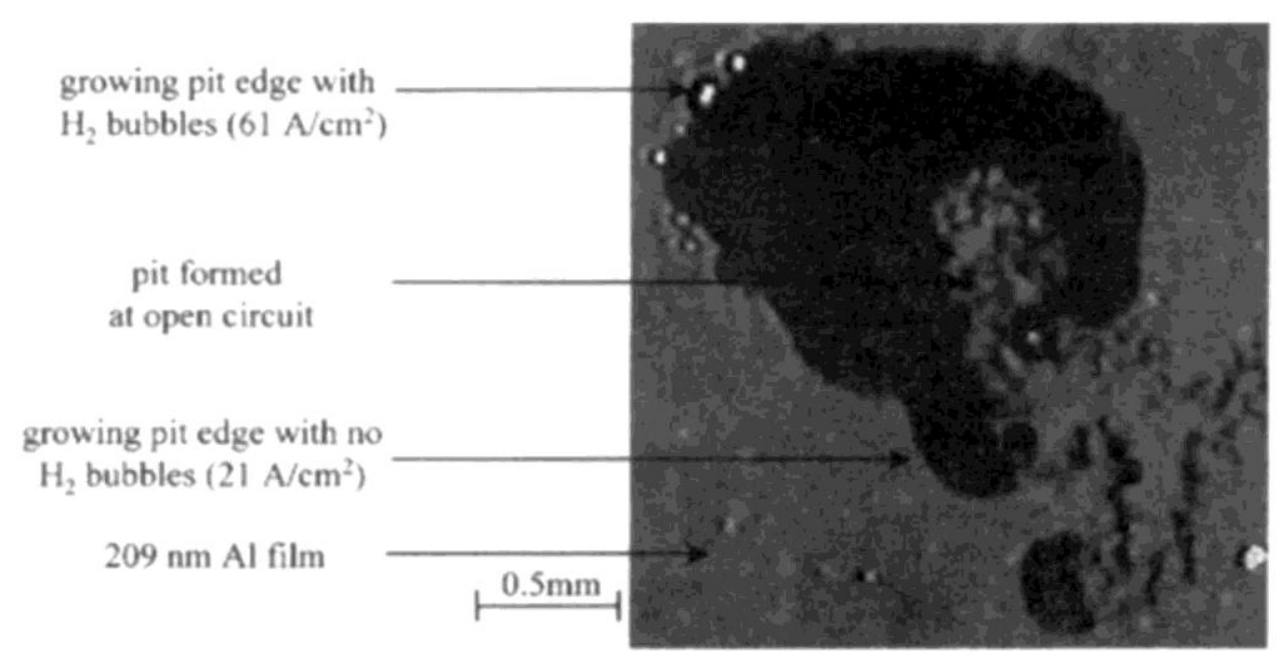

Fig. 6. Video image of a pit growing in $1 \mathrm{M} \mathrm{NaCl}+0.5 \mathrm{M} \mathrm{Na}_{2} \mathrm{Cr}_{2} \mathrm{O}_{7}$ at $-550 \mathrm{mV} \mathrm{SCE}$. 


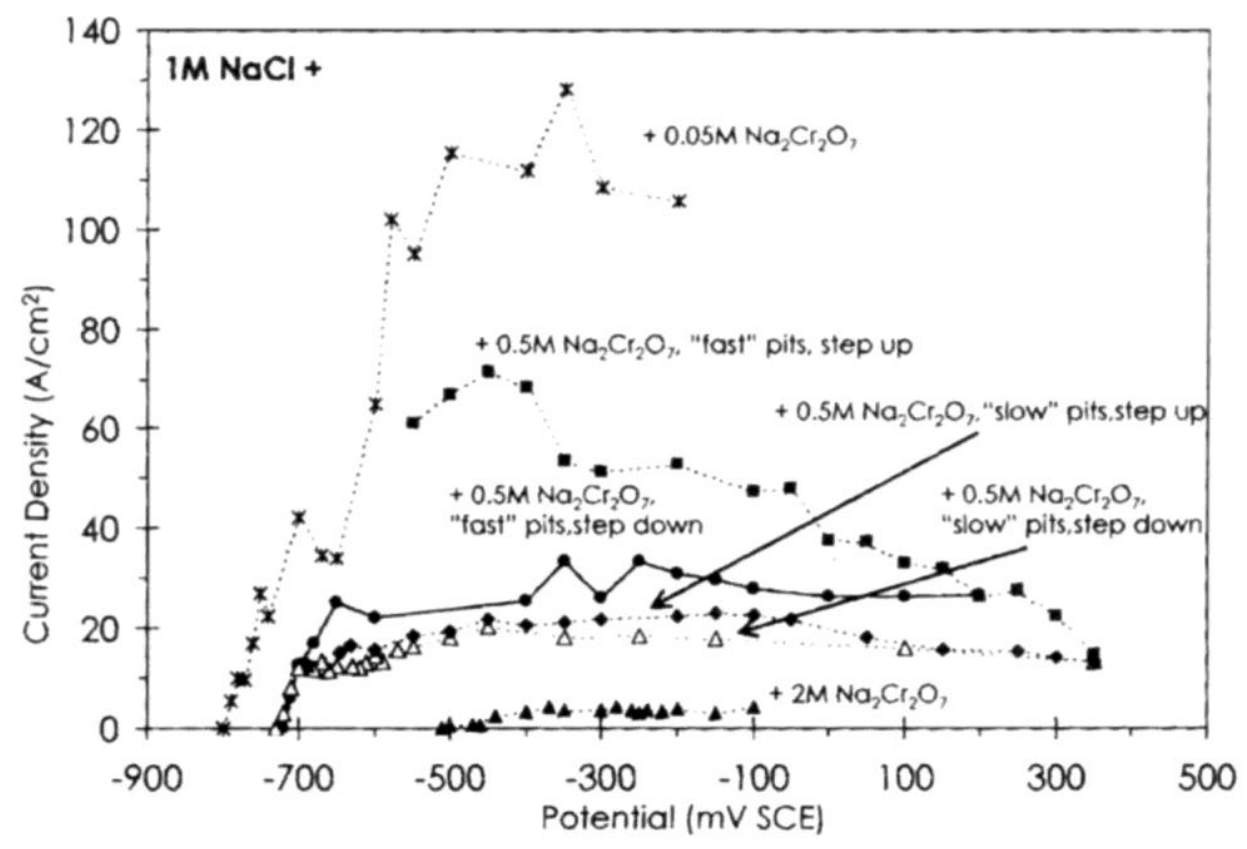

Fig. 7. Average anodic pit current density as a function of applied potential for pits in $209 \mathrm{~nm}$ thick Al films in 1.0 M NaCl with varying amounts of $\mathrm{Na}_{2} \mathrm{Cr}_{2} \mathrm{O}_{7}$.

The current density of pits in solutions with chloride + dichromate was determined as a function of applied potential as was done for the case of pure chloride solutions described above. Figure 7 shows the pit polarization curves in $1 \mathrm{M} \mathrm{NaCl}$ solutions containing varying amounts of $\mathrm{Na}_{2} \mathrm{Cr}_{2} \mathrm{O}_{7}$. Dichromate ions increase the repassivation potential $\left(E_{\mathrm{R}}\right)$ by about $150 \mathrm{mV}$ for $0.1 \mathrm{M}$ $\mathrm{Cl}$ solutions and about $90 \mathrm{mV}$ for most concentrations in $1.0 \mathrm{M} \mathrm{Cl}$. This is one indication of the benefit of dissolved dichromate ions for inhibiting pit growth in spite of the formation of opencircuit pits in dichromate-containing solutions. Only the step-down experiments were performed in $1 \mathrm{M} \mathrm{NaCl}+0.05 \mathrm{M} \mathrm{Na}_{2} \mathrm{Cr}_{2} \mathrm{O}_{7}$. The pit current density was similar to that for pure $1 \mathrm{M} \mathrm{NaCl}$, and even somewhat larger at potentials above $-500 \mathrm{mV}$ SCE. Apparently, no effect on the pit growth rate is observed if the chromate concentration is sufficiently small.

The data for pits in $1 \mathrm{M} \mathrm{NaCl}+0.5 \mathrm{M} \mathrm{Na}_{2} \mathrm{Cr}_{2} \mathrm{O}_{7}$ are divided in Fig. 7 into step-up and step-down experiments. Furthermore, the measurements made for "slow" growth that initiated at the initial open-circuit pits with no hydrogen gas bubbles, are separated from "fast" growth that occurs with hydrogen bubbles at the retreating pit edge. The fast pits with hydrogen at the pit walls behave similarly in the step-up experiments to pure $1 \mathrm{M} \mathrm{NaCl}$ solutions. The peak current density is somewhat smaller, but the slow decrease in pit current density at higher potentials is identical to the $1.0 \mathrm{M} \mathrm{NaCl}$ case. The step-down behavior of these pits is closer to that of the 0.1 $M$ case in that the limiting current density is maintained to low potential values and a large hysteresis is observed. In contrast, the slow growing pits without hydrogen bubbles at the edge never reach high current density values and no hysteresis is seen. Clearly the mass-transport conditions play a significant role in the behavior of these pits. The slow pits have a tenacious passive film remnant at the pit edge, so that mass transport is inhibited relative to the case where the passive film is lifted up at the pit edge by hydrogen bubbles. It is not clear at this point what controls the tenacity of the passive film remnant. This is a local property since different regions 
on the same pit can behave differently. It is possible that whether the passive film remnant remains tenaciously adhered at the pit edge or is lifted up away from the edge depends on the initial condition when the pit starts to grow. The repassivated open-circuit pits provide a ready crevice for the initiation of pit growth so that the bubbles that form when pit growth restarts may tend to exit from the pre-existing breaks in the passive film as shown in Fig. 5b. If bubbles large enough to break the passive film remnant never form, this would lead to sustained growth at low current. On the other hand, if bubbles start breaking the film away as soon as the pit is initiated, pit growth may continue with the undermined passive film continually being broken and lifted, and the pit growth rate remaining high.

Figure 7 also shows that in a $1 \mathrm{M} \mathrm{NaCl}+2 \mathrm{M} \mathrm{Na}_{2} \mathrm{Cr}_{2} \mathrm{O}_{7}$ solution, only very small pit growth rates were observed. It should be noted that this bulk solution is almost saturated to begin with, so that salt film precipitation would easily occur. It is expected that the salt films that precipitate in the chloride + dichromate solutions contain $\mathrm{Cr}$ (III) ions in some form that have reduced from the dichromate since the pit wall potential is so far below the reversible potential for this reaction.

In order to investigate higher dichromatexhloride ratios, it was necessary to use lower chloride concentrations. When the dichromate/chloride ratio was sufficiently high, pits would not initiate or grow. For instance, in a $0.01 \mathrm{M} \mathrm{NaCl}+0.05 \mathrm{M} \mathrm{Na}_{2} \mathrm{Cr}_{2} \mathrm{O}_{7}$ solution, no pits were initiated even though the potential was scanned up to $+2 \mathrm{~V} \mathrm{SCE}$. An alternate approach was used in an attempt to study pit growth in this solution. The applied potential of a sample in $0.01 \mathrm{M}$ $\mathrm{NaCl}$ was jumped from open circuit to different potentials as high as $+2 \mathrm{~V}$ SCE, at which point many pits initiated quickly. A measured amount of concentrated dichromate solution was then injected with a syringe to make a bulk solution of $0.01 \mathrm{M} \mathrm{NaCl}+0.05 \mathrm{M} \mathrm{Na}_{2} \mathrm{Cr}_{2} \mathrm{O}_{7}$. Gas purging was used to aid mixing and equilibration of the solutions. The pits that were initiated in $0.01 \mathrm{M}$ $\mathrm{NaCl}$ continued growing for $4 \mathrm{~s}$ while mixing of the dichromate into the solution was taking place, and then suddenly froze, and stopped growing. At that point the solution was observed to be well mixed with a uniform appearance and a noticeable decrease in the number of density gradient streaks that were evident as the concentrated, red-colored dichromate solution was mixing in. Even subsequent stepping of the potential to $+2 \mathrm{~V}$ could not make the pits grow further.

The data presented above indicate that the dichromatexhloride molar ratio of $0.5: 1$ in $1 \mathrm{M}$ $\mathrm{Cl}^{-}$solutions has only a minor effect on thin film pit growth if the slow pit growth associated with open-circuit pits is disregarded. At a molar ratio of 2:1 pit growth is significantly reduced, and at a ratio of 5:1 pit growth would not have been possible. These ratios, however, are dependent on the chloride concentration. For instance, pits will grow in a $0.1 \mathrm{M} \mathrm{NaCl}+0.5 \mathrm{M}$ $\mathrm{Na}_{2} \mathrm{Cr}_{2} \mathrm{O}_{7}$ solution, which also has a 5:1 molar ratio. Given the trend of increasing dichromatexhloride ratio needed to affect pitting with increasing scale of the pitting, as described in the introduction, it is somewhat surprising that the ratio needed to affect thin film pit growth is almost the same as that needed to affect the growth of $0.2 \mathrm{~mm}$ deep pits. ${ }^{5}$

Sulfate-containing solutions.-The effects of adding $\mathrm{Na}_{2} \mathrm{SO}_{4}$ to $0.1 \mathrm{M} \mathrm{NaCl}$ on the pit growth rates are shown in Fig. 8. All the data reported in this figure are step-down measurements. The addition of $0.05 \mathrm{M} \mathrm{Na}_{2} \mathrm{SO}_{4}$ has a small effect in the low potential region, whereas the pit growth rates increase substantially when $0.2 \mathrm{M} \mathrm{Na}_{2} \mathrm{SO}_{4}$ is added. The conductivity of the $0.1 \mathrm{M} \mathrm{NaCl}$ increases as $\mathrm{Na}_{2} \mathrm{SO}_{4}$ is added; Table I gives various properties of the solutions examined, as well as the characteristic potentials of $209 \mathrm{~nm}$ Al thin films in the 
solutions. The increased pit current densities in the $0.1 \mathrm{M} \mathrm{NaCl}+0.2 \mathrm{M} \mathrm{Na}_{2} \mathrm{SO}_{4}$ solution certainly result from the increase in bulk solution conductivity compared to $0.1 \mathrm{M} \mathrm{NaCl}$.

The addition of $0.2 \mathrm{M}$ sulfate reduced the repassivation potential by a small amount, and smaller concentrations had almost no effect. However, sulfate additions had a remarkable effect on the pitting potentials. For example, the addition of $0.05 \mathrm{M} \mathrm{Na}_{2} \mathrm{SO}_{4}$ to $0.1 \mathrm{M} \mathrm{NaCl}$ resulted in an increase in the pitting potential of almost $400 \mathrm{mV}$ to around $-200 \mathrm{mV} \mathrm{SCE}$, and no change in the repassivation potential of $-725 \mathrm{mV}$ SCE. The reason for this behavior is not clear. The increase in pitting potential cannot be attributed to pit growth considerations since sulfate increases pit growth rates. Sulfate ions are typically not thought to affect the passive film properties. An explanation for the influence of sulfate will require further work.

Implications of the findings. - Two of the critical aspects of growing pits in Al samples of any size are the copious evolution of hydrogen gas in the pit and the role of the undermined passive film, which can act as a pit cover and transport barrier. These aspects are highlighted, and possibly exaggerated in pits in thin films. Because the anodic current densities are high for pits in thin films, the hydrogen evolution current densities are correspondingly high and relatively large amounts of hydrogen bubbles are generated. Furthermore, the close proximity of the entire active pit surface to the undermined passive film allows this film to have a significant influence on pit growth rates for thin film samples. The effects of hydrogen and the remnant passive film are easier to control and assess for pits in thin films compared to those in bulk samples. They are shown in this work to affect both mass transport and ohmic potential considerations.

The observation of a large current density hysteresis is evidence of some role of supersaturation and salt film precipitation. It is not clear to what extent these phenomena occur in pits in bulk samples. However, the observations in this work suggest that they may be important for small pits. The fact that large amounts of chromate are required before the $2 \mathrm{D}$ pit growth rate is affected is interesting in light of observations that very small concentrations of chromate in chloride solutions can have large effects on the pitting behavior of $\mathrm{Al}$ alloys. ${ }^{12}$ As described above, the amount of chromate required to affect pitting seems to increase as the scale of pitting increases. ${ }^{5-7}$ Assuming that pits in thin films act like small pits in bulk samples, one might expect that only small concentrations of chromate would be needed to influence pitting in the thin films. The observation that large amounts of chromate are required to reduce the rate of pit growth even in thin films suggests that chromate does not inhibit pitting by acting as a strong anodic inhibitor and reducing pit growth rates. Other possible roles of chromate are currently under investigation. 


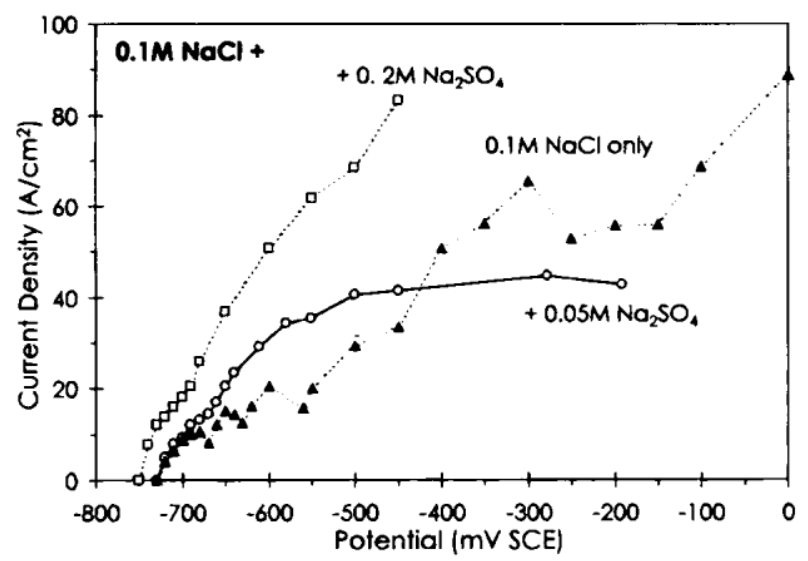

Fig. 8. Average anodic pit current density as a function of applied potential for pits in $209 \mathbf{~} \mathbf{m}$ thick Al films in $0.1 \mathrm{M} \mathrm{NaCl}$ with varying amounts of $\mathrm{Na}_{2} \mathrm{SO}_{4}$.

Table I. Properties of solutions examined, and open circuit pitting, and repassivation potentials of $209 \mathrm{~nm}$ Al thin films in the solutions. The mean potentials are reported along with their standard deviations. Note that large metastable pits form at open circuit in the dichromate-containing solutions, but the pitting potentials given are for the initiation of stable pits.

\begin{tabular}{|c|c|c|c|c|c|}
\hline Solution & $\mathrm{pH}$ & $\begin{array}{l}\text { Conductivity } \\
\left(\Omega^{-1} \mathrm{~cm}^{-1}\right)\end{array}$ & $\frac{E_{\mathrm{OC}}}{(\mathrm{mV} \text { SCE})}$ & $\underset{(m V ~ S C E)}{E_{\mathrm{P}}}$ & $(\mathrm{mV} \mathrm{SCE})$ \\
\hline $\begin{array}{l}\text { 1.0 M NaCl } \\
1.0 \mathrm{M} \mathrm{NaCl}+0.05 \mathrm{M} \mathrm{Na}_{2} \mathrm{Cr}_{2} \mathrm{O}_{7} \\
1.0 \mathrm{M} \mathrm{NaCl}+0.5 \mathrm{M} \mathrm{Na}_{2} \mathrm{Cr}_{2} \mathrm{O}_{7} \\
1.0 \mathrm{M} \mathrm{NaCl}+2.0 \mathrm{M} \mathrm{Na}_{2} \mathrm{Cr}_{2} \mathrm{O}_{7} \\
1.0 \mathrm{M} \mathrm{NaCl}+0.5 \mathrm{M} \mathrm{Na}_{2} \mathrm{SO}_{4}\end{array}$ & $\begin{array}{l}5.84 \\
3.96 \\
4.28 \\
4.07 \\
7.44\end{array}$ & $\begin{array}{l}0.0792 \\
0.085 \\
0.1131 \\
0.1338 \\
0.1043\end{array}$ & $\begin{aligned}-863 & \pm 120 \\
-790 & \pm 0 \\
-699 & \pm 4 \\
-514 & \pm 31 \\
-1000 & \pm 85\end{aligned}$ & $\begin{array}{l}-672 \pm 53 \\
-642 \pm 94 \\
-655 \pm 19 \\
-298 \pm 20 \\
-291 \pm 109\end{array}$ & $\begin{array}{l}-806 \pm 5 \\
-790 \pm 10 \\
-716 \pm 5 \\
-503 \pm 12 \\
-810 \pm 0\end{array}$ \\
\hline $\begin{array}{l}0.1 \mathrm{M} \mathrm{NaCl} \\
0.1 \mathrm{M} \mathrm{NaCl}+0.05 \mathrm{M} \mathrm{Na}_{2} \mathrm{Cr}_{2} \mathrm{O}_{7} \\
0.1 \mathrm{M} \mathrm{NaCl}+0.2 \mathrm{M} \mathrm{Na}_{2} \mathrm{Cr}_{2} \mathrm{O}_{7} \\
0.1 \mathrm{M} \mathrm{NaCl}+0.05 \mathrm{M} \mathrm{Na}_{2} \mathrm{SO}_{4} \\
0.1 \mathrm{M} \mathrm{NaCl}+0.2 \mathrm{M} \mathrm{Na}_{2} \mathrm{SO}_{4}\end{array}$ & $\begin{array}{l}6.10 \\
4.31 \\
4.38 \\
6.24 \\
6.75\end{array}$ & $\begin{array}{l}0.0113 \\
0.0197 \\
0.0392 \\
0.0211 \\
0.0372\end{array}$ & $\begin{array}{l}-757 \pm 67 \\
-572 \pm 9 \\
-562 \pm 4 \\
-756 \pm 105 \\
-860 \pm 175\end{array}$ & $\begin{array}{l}-597 \pm 45 \\
-545 \pm 27 \\
-541 \pm 18 \\
-199 \pm 66 \\
-166 \pm 108\end{array}$ & $\begin{array}{l}-726 \pm 5 \\
-583 \pm 10 \\
-563 \pm 8 \\
-728 \pm 5 \\
-738 \pm 5\end{array}$ \\
\hline
\end{tabular}

\section{Conclusions}

Pit growth in $209 \mathrm{~nm}$ thick Al films was studied over a wide range of applied potential using image analysis of the growing pits to determine pit current density. The following observations were made.

1. In chloride solutions, the pit current density initially increased as the applied current density increased. A maximum pit current density was observed followed by a decrease to lower values as the applied potential was further increased. At the highest applied potentials the pit current density was almost independent of potential.

2. A hysteresis in the pit polarization curve was found for samples whose potential was stepped downward from high values. This hysteresis is thought to be a result of a combination of supersaturation followed by salt film formation, and changes in mass transport from hydrogen bubbles that increase convection and lift the remnant passive film away from the dissolving surface. 
3. In dichromate-containing chloride solutions, the corrosion and repassivation potentials shifted in the noble direction, and rather large metastable pits formed at open circuit. These metastable pits act as sites for initiation of further pitting at higher applied potentials. The pit current densities associated with these pits that initiate at the open-circuit metastable pits are lower because of a remnant passive film that is not lifted away from the surface and acts as a barrier for mass transport.

4. High dichromate:chloride ratios are required to affect 2D pit growth in thin films.

\section{Acknowledgments}

This work was supported by Major H. DeLong at the United States Air Force Office of Scientific Research under contract F49620-96-0042.

The Ohio State University assisted in meeting the publication costs of this article.

\section{REFERENCES}

1. G.S. Frankel, Corros. Sci., 30, 1203 (1990).

2. G.S. Frankel, J. O. Dukovic, B. M. Rush, V. Brusic, C.V. Jahnes, J. Electrochem. Soc., 139, 2196 (1992).

3. G.S. Frankel, R. C. Newman, C. V. Jahnes, and M. A. Russak, J. Electrochem. Soc., 140, 2192 (1993).

4. G.S. Frankel, J. R. Scully, and C. V. Jahnes, J. Electrochem. Soc., 143, 1834 (1996).

5. F. Hunkeler and H. Bohni, Corrosion, 37, 645 (1981).

6. H. Kaesche, in Localized Corrosion, R. W. Staehle, B. F Brown, J. Kruger, and A. Agraswal, Editors, National Association of Corrostion Engineers, NACE-3, p. 516, NACE, Houston, TX (1974).

7. S.T. Pride, J. R. Scully, and J. L. Judson, J. Electrochem. Soc., 141, 3028 (1994).

8. H. S. Isaacs and R. C. Newman, in Corrosion Chemistry within Pits, Crevices, and Cracks, A. Turnbull, Editor, p. 45, HMSO Books, London (1987).

9. T.R. Beck, Electrochim. Acta, 29, 485 (1984).

10. A. Turnbull, Corros. Sci., 23, 883 (1983).

11. M. Pourbaix, Atlas of Electrochemical Equilibria in Aqueous Solutions, National Association of Corrosion Engineers, NACE, Houston, TX (1974).

12. J. Zhao, G. S. Frankel, and R. L. McCreery, J. Electrochem. Soc., 145, 2258 (1998). 